Etnográfica

Revista do Centro em Rede de Investigação em

Antropologia

vol. 25 (1) | 2021

Vol. $25(1)$

\title{
O património alimentar enquanto atração turística: a conversão da Dieta Mediterrânica em mercadoria, em Chefchaouen (Marrocos)
}

Food heritage as a tourist attraction: the commodification of the Mediterranean Diet, in Chefchaouen (Morocco)

Joana Lucas

\section{(2) OpenEdition}

\section{Journals}

\section{Edição electrónica}

URL: https://journals.openedition.org/etnografica/10056

DOI: 10.4000/etnografica. 10056

ISSN: 2182-2891

\section{Editora}

Centro em Rede de Investigação em Antropologia

Edição impressa

Paginação: 231-253

ISSN: 0873-6561

\section{Refêrencia eletrónica}

Joana Lucas, «O património alimentar enquanto atração turística: a conversão da Dieta Mediterrânica em mercadoria, em Chefchaouen (Marrocos)», Etnográfica [Online], vol. 25 (1) | 2021, posto online no dia 05 março 2021, consultado o 29 janeiro 2022. URL: http://journals.openedition.org/etnografica/ 10056 ; DOI: https://doi.org/10.4000/etnografica. 10056

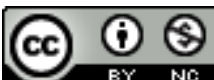

Etnográfica is licensed under a Creative Commons Attribution-NonCommercial 4.0 International License. 


\section{O património alimentar enquanto atração turística: a conversão da Dieta Mediterrânica em mercadoria, em Chefchaouen (Marrocos)}

\section{Joana Lucas}

Partindo da classificação da Dieta Mediterrânica enquanto património cultural imaterial pela UNESCO, este artigo procura refletir sobre os processos de conversão em mercadoria para fins turísticos daí decorrentes, bem como sobre a invenção local de uma gastronomia que se considera espelhar as práticas e os pressupostos da Dieta Mediterrânica. Centrando-se geograficamente em Chefchaouen (Marrocos), a etnografia realizada permite afirmar que os processos de conceção, invenção e transfiguração patrimoniais não estão fora do controlo das comunidades locais, prestando igualmente atenção à dimensão heterogénea e plural não só das próprias comunidades, como também das suas expetativas perante as eventuais vantagens associadas a uma classificação patrimonial.

PALAVRAS-CHAVE: alimentação, turismo, património imaterial, Dieta Mediterrânica, Marrocos.

Food heritage as a tourist attraction: the commodification of the Mediterranean Diet, in Chefchaouen (Morocco) - Based on the classification of the Mediterranean Diet as intangible cultural heritage by UNESCO, this article seeks to reflect on the processes of commodification for tourist purposes resulting from it, as well as on the local invention of a gastronomy that is considered to reflect the practices and the assumptions of the Mediterranean Diet. Focusing geographically in Chefchaouen (Morocco), the ethnography carried out allows us to affirm that the processes of heritage conception, invention and transfiguration are not beyond the control of local communities, paying also attention to the heterogeneous and plural dimension not only of the communities themselves, but also their expectations regarding the possible advantages associated with an heritage classification.

KEYWORDS: food, tourism, intangible heritage, Mediterranean Diet, Morocco.

LUCAS, Joana (joana.i.lucas@gmail.com) - CRIA-FCSH-UNL, Portugal. 


\section{PREÂMBULO}

A nova ordem patrimonial, na qual o património cultural e imaterial tem assumido um papel central e aglutinador, tem servido simultaneamente de mote e de motor para a criação de novas atrações turísticas, a diferentes ritmos e escalas, um pouco por todo o mundo. Os recentes e crescentes anseios e expetativas que têm por objetivo a participação na criação e classificação de elementos patrimoniais, nomeadamente junto de instituições como a UNESCO, são fenómenos em relação aos quais a antropologia tem prestado atenção - sendo também, tantas vezes, parte ativa nesses processos - e que se têm estendido a diversas esferas, entre as quais a dos consumos e práticas alimentares.

Efetivamente, a par com uma prolífica produção teórica sobre património material e imaterial, ${ }^{1}$ a reflexão sobre a especificidade da alimentação enquanto património cultural tem igualmente começado a dar os seus frutos, como se pode verificar através do volume organizado por Brulotte e Di Giovine (2014), ou aquele organizado por Lum e Le Vayer (2016), no qual os efeitos da classificação de práticas e produtos alimentares enquanto património pela UNESCO (Coreia do Sul, México, Espanha) são já discutidos.

Desta forma, é objetivo deste texto pensar e discutir a criação de produtos e atrações turísticas a partir de classificações patrimoniais que tenham por objeto elementos e práticas alimentares, centrando-se na classificação da Dieta Mediterrânica ${ }^{2}$ enquanto património cultural imaterial da humanidade pela UNESCO - candidatura transnacional protagonizada por sete países (Portugal, Espanha, Itália, Grécia, Chipre, Croácia e Marrocos) - e ancorando-se etnograficamente na região de Chefchaouen (Marrocos), ${ }^{3}$ uma das "comunidades representativas" ${ }^{4}$ da candidatura.

I O volume organizado por Arizpe e Amescua (2013) constitui um bom ponto de partida na discussão das questões levantadas globalmente pela crescente importância (e volume) das classificações de património cultural e imaterial no contexto atual. Não obstante, a reflexão crítica sobre os processos de patrimonialização tem sido prolífica nas últimas décadas, como se pode comprovar através das publicações de Smith (2006), Ruggles e Silverman (2009), Smith e Akagawa (2009), Bendix, Eggert e Peselmann (2012), Harrison (2013), Labadi (2013), entre outras.

2 A inscrição da Dieta Mediterrânica enquanto património cultural imaterial pela UNESCO ocorre em dois momentos distintos: o primeiro em 2010, num dossiê submetido por Espanha, Marrocos, Itália e Grécia (5.COM, Nomination File 00394); e o segundo em 2013, uma reinscrição à qual se juntam Portugal, Chipre e Croácia (8.COM, Nomination File 00884).

3 O trabalho de campo etnográfico realizado em Chefchaouen, em julho de 2017 e em outubro de 2018, contou com o apoio da Fundação para a Ciência e a Tecnologia (no âmbito da bolsa de pós-doutoramento SFRH/BPD/10831 1/2015) e do Centre Jacques Berque de Rabat (USR 3136).

4 Cada país envolvido na candidatura teve de indicar a "cidade representativa" da Dieta Mediterrânica à escala nacional. Assim, existem sete cidades representativas da Dieta Mediterrânica: Chefchaouen (Marrocos), Tavira (Portugal), Sória (Espanha), Cilento (Itália), Koroni (Grécia), Agros (Chipre), Kvar e Brac (Croácia). 
No caso da Dieta Mediterrânica será importante perceber se a narrativa transnacional ligada à alimentação, para além de estar presente nos materiais da candidatura apresentada à UNESCO é, efetivamente, operativa às escalas nacionais e regionais. Por outras palavras: como se procura capitalizar a classificação da Dieta Mediterrânica em património alimentar?

Este texto, ao centrar-se na análise de um território que deu origem a uma classificação patrimonial, fá-lo, em grande medida, à luz daquilo que entendemos constituir-se enquanto iniciativas de transformação da Dieta Mediterrânica em produto/mercadoria, e que são visíveis, com especial ênfase, no plano da promoção turística. Finalmente, procurar-se-á perceber como se constrói localmente uma ideia de (e um mercado para a) Dieta Mediterrânica, e que estratégias e mecanismos são usados para o efeito.

Assim, a partir da constatação de que a economia política da patrimonialização funciona, regra geral, de cima para baixo (Crooke 2010; Smith 2006), pretendo aqui discutir os processos através dos quais as populações locais munidas, manifestamente, de aspirações e estratégias diversas - procuram (ou não) participar na criação de atrações turísticas, e/ou beneficiar da transformação de eventuais elementos patrimoniais em produtos que possam ser promovidos e vendidos. Acredito que a invenção de atrações turísticas a partir da retórica e da linguagem da patrimonialização e, consequentemente, da praxis daí decorrente, se podem traduzir num desafio do turístico - mote para este dossiê temático - em relação ao qual a antropologia e a prática etnográfica terão um contributo a dar.

Entendendo que a arena das classificações patrimoniais é fortemente disputada, competindo nela vários atores pelas vantagens associadas à validação do património, e tendo em conta que não são apenas os grupos dominantes que cobiçam os eventuais benefícios que as classificações patrimoniais prenunciam, irei propor que os processos de conceção do património (desde a sua mise en auvre à sua mise en scène) não estão fora do controlo das comunidades.

Esta sugestão, que o trabalho de campo etnográfico realizado parece vir confirmar, acompanha Pfeilstetter (2015) quando refere que a atenção - ao pensarmos sobre o papel da agência na criação de património cultural ${ }^{5}$ - não deve estar centrada na tentativa de distinção entre "detentores de património" e "praticantes do património", mas antes na problematização da ideia de "empreendedorismo patrimonial", e dos seus múltiplos atores, expetativas e possibilidades de apropriação.

No entanto, se considerarmos que a definição de Pfeilstetter (2015) para "empreendedorismo patrimonial" é operativa e funcional tendo em conta a realidade observada em Chefchaouen, a abordagem que aqui se pretende

5 Acompanhando aqui a proposta de Kirshenblatt-Gimblett (2004), a partir da qual os processos patrimoniais são, na sua essência, processos de curadoria da cultura. 
realizar foge ao universo discutido pelo autor - que se foca exclusivamente na conceção e construção institucionalizada do património. Para Pfeilstetter, "empreendedorismo patrimonial" é uma formulação que "[...] aborda o caráter competitivo, conflituoso e marcado pela agência, do património cultural" (2015: 215), entendendo ao mesmo tempo o conceito de empreendedorismo como "[...] um processo de mudança social promovido pela institucionalização de ideias inovadoras e/ou antagónicas numa sociedade" (2015: 219).

Desta forma, a distinção entre "detentores do património" e "praticantes do património", tal como é realizada por Pfeilstetter, revelou-se operativa (e útil) tendo em conta o contexto e as especificidades de Chefchaouen, tomando-os - detentores e praticantes - enquanto atores que mobilizam diferentes práticas e discursos perante as possibilidades de transformação do património em mercadoria, mas igualmente como categorias plásticas e permeáveis e, sobretudo, não exclusivas e estanques.

Assim, este texto insistirá na premissa de que os processos de construção/ invenção/transformação do património não estão fora do controlo das comunidades - considerando neste sentido todas as suas pluralidades e diferenças - e procurará, não perdendo de vista o conceito de "empreendedorismo patrimonial", verificar a sua possibilidade de adaptação a outros grupos e interlocutores que não apenas aqueles ligados ou integrando instituições.

Mais concretamente, este texto procurará perceber como se articula, em Chefchaouen, a transformação da Dieta Mediterrânica - enquanto conjunto diverso de práticas e consumos alimentares - em produto/mercadoria, no domínio específico da promoção turística, e naquele que é o terreno disputado dos eventuais benefícios patrimoniais.

\section{CHEFCHAOUEN}

Situada no noroeste de Marrocos, Chefchaouen está inserida na região montanhosa do Rife, a uma altitude de 600 metros, sendo limitada a norte pelo Mediterrâneo. A sua zona circundante é rica em florestas de sobreiros e abetos, localizando-se nas proximidades de um parque nacional (Talassemtane) ${ }^{6}$ e junto a um parque natural (Bouhachem). ${ }^{7}$ A cidade desenvolveu-se em

6 Classificado pela UNESCO em 1998 enquanto património natural, o Parque Nacional Talassemtane é constituído por uma floresta endémica maioritariamente composta por pinheiros (Abies maroccana) e cedros (Cedrus atlantica).

7 Compreendendo uma área de 105.470 hectares, o parque natural de Bouhachem tem uma flora predominantemente composta por diferentes espécies de carvalho (Quercus faginea, Quercus pyrenaica, Quercus suber), e uma fauna diversificada da qual constam 34 espécies de mamíferos. Criado recentemente (2015) enquanto parte de medidas de combate às alterações climáticas em Marrocos, este parque terá sido inspirado pelo parque natural francês do Lubéron, e resulta de uma colaboração entre a região marroquina de Tânger-Tétuan com a região francesa de Provence-Alpes-Côte d'Azur. 
torno de uma medina ${ }^{8}$ de cerca de dez quilómetros quadrados, cuja edificação remonta ao século XV e que, sendo totalmente pedonal, constitui a principal atração turística da cidade.

Chefchaouen está etnicamente inserida no Pays Jbala, que geograficamente se estende desde o estreito de Gibraltar até Taza, lugar onde as montanhas do Rife e do Médio Atlas se encontram. Os jbala são um grupo étnico de origem amazigh do Norte de Marrocos, sendo a palavra "jbala" o plural de "jebli", que significa "da montanha". No entanto, outro termo pode ser utilizado para caraterizar etnicamente os habitantes desta região: ghomara. ${ }^{9}$ Esta designação - consagrada pela história medieval - terá sido progressivamente substituída (eventualmente a partir do séc. XVI) (Vignet-Zunz 2014) pela de jbala. Herdeiros de um território marcado pela predominância de uma agricultura de subsistência os jbala/ghomara são frequentemente caraterizados pela sua hábil gestão dos recursos agrícolas, e por manterem uma forte relação com a terra, algo que legitima a ideia da preexistência de um modelo alimentar e gastronómico específico e singular na região.

No dossiê de candidatura apresentado em 2010 junto da UNESCO, Chefchaouen é descrita a partir da enfatização do seu passado multicultural e inter-religioso, mas também enquanto modelo de biodiversidade e sustentabilidade. ${ }^{10}$ No discurso ali mobilizado, diversidade cultural e diversidade biológica apresentam-se como as duas faces da retórica patrimonial: o binómio natureza/ cultura integra e incorpora de forma cada vez mais evidente e acentuada as narrativas patrimoniais da UNESCO, que procuram glorificar discursivamente uma ideia de diversidade (cultural e biológica) que pode ser apreendida e valorizada por via da patrimonialização.

8 A palavra "medina", que significa cidade em árabe (madina), será utilizada ao longo deste texto para descrever a parte antiga das cidades magrebinas.

9 Para uma leitura mais aprofundada sobre os jbala/ghomara ver, por exemplo: AA.VV., 1995, Encyclopédie Berbère. Vol. XVI: Djalut - Dougga, Aix-en-Provence, Edisud; ou AA.VV., 1991, Jbala - Histoire et Société: Etudes sur le Maroc du Nord-Ouest. Groupe pluridisciplinaire d'étude sur les Jbala, Paris, Editions du CNRS.

10 Nesse documento, podemos ler: "The community of Chefchaouen has a population of 54.562 inhabitants (2008). Since its foundation in 1471, its Jbala residents have welcomed the Moriscos (Muslims converted to Christianity) and the Sephardic Jews who left the Spanish Andalusia at the time of the Reconquista, making out of it over the years a very representative culture in northern Morocco. Chefchaouen is a model of biodiversity of great environmental importance. The wise management of these resources by the community of Chefchaouen is reflected by the Mediterranean Diet, by the close relation, from the landscape to the cuisine, between the people and the land. This element appears as a major expression of the individual and collective identity of the members of this community, in which the women potters, with their millenary knowledge, continue to ensure the essential artisanal component of this element." (UNESCO 2010, Nomination File 003 $94,3)$. 
Chefchaouen é um dos territórios turísticos rurais mais emblemáticos de Marrocos, ${ }^{11}$ quer para o turismo internacional, quer para o turismo interno, onde se tem afirmado ao longo dos últimos anos como um dos destinos que fazem parte das preferências dos turistas marroquinos, ${ }^{12}$ sendo o turismo um dos principais setores de atividade económica na região.

Dados de 2015 apontam para o registo de 46.253 chegadas a estabelecimentos turísticos classificados em Chefchaouen, de onde 17.589 correspondem a turistas não residentes em Marrocos, e 28.664 correspondem a turistas residentes (Observatoire du Tourisme Maroc 2015a), tendo o turismo interno, tomando estes dados, um peso de $62 \%$ na atividade turística desenvolvida na localidade. Dados relativos a 2017 emitidos pela Delegação Provincial de Turismo apontam para um total de 28.619 turistas internacionais (dos quais 13.600 oriundos da China) durante os primeiros dez meses do ano, e de 12.001 turistas internos, uma diminuição de $20 \%$ em comparação com o mesmo período de 2016 (Aujourd'hui Le Maroc, 3 de janeiro de 2018), ${ }^{13}$ numa quase inversão estatística de proveniências em comparação com os dados de 2015.

Em termos de infraestruturas turísticas, Chefchaouen dispõe de 37 hotéis, 20 pensões, 51 casas de hóspedes e 20 casas rurais, num total de 3400 camas, e de um total de 60 estabelecimentos de restauração, entre os quais 53 restaurantes e sete negócios de fast-food. ${ }^{14}$

Chefchaouen constitui-se sobretudo enquanto um expressivo destino de turismo rural, no contexto de uma "febre turística" que tomou de assalto o universo rural marroquino (Berriane e Moizo 2016), como alternativa aos des-

Il Conhecida como a perle bleue, Chefchaouen consolidou-se enquanto destino turístico em grande medida graças às caraterísticas da sua medina (pitoresca, rústica e pintada de cal com pigmentos de cobalto), mas sobretudo devido à sua pequena dimensão, o que a transforma facilmente num lugar familiar, que pode ser percorrido e reconhecido com facilidade. Não obstante, haverá que referir também que a sua proximidade em relação à Europa contribuiu para a popularização de alguns fluxos de turistas europeus, nomeadamente de turistas espanhóis.

12 Numa lista encabeçada por Marraquexe $\left(1 .{ }^{\circ}\right)$, Agadir $\left(2 .^{\circ}\right)$, Tânger $\left(3 .^{\circ}\right)$, Casablanca $\left(4 .^{\circ}\right)$ e Fez $\left(5^{\circ}\right)$ (Observatoire du Tourisme Maroc, 2015b).

$13 \mathrm{Em}<$ http://aujourdhui.ma/economie/tourisme-les-chinois-charmes-par-chefchaouen > (última consulta em fevereiro de 2021). Durante a estadia de trabalho de campo um comerciante referiu que a diminuição de turistas marroquinos observada no verão de 2017 estaria relacionada com os acontecimentos em Al-Hoceima. Em outubro de 2016, Al-Hoceima (cidade no norte de Marrocos, junto da costa mediterrânica) foi palco de um movimento de contestação que ficou conhecido como Hirak Rif, que já levou à prisão de mais de 200 pessoas. O Hirak, enquanto movimento de protesto, foca-se em reivindicações por mais oportunidades de emprego, bem como pela exigência de infraestruturas sociais como hospitais e escolas.

14 Os dados sobre hotelaria e restauração em Chefchaouen forem obtidos no terreno, nomeadamente em Annuaire Statistique - Octobre 2015 - Septembre 2016, Programme d'Appui à la Stratégie Municipale de Tourisme des Communes de Chefchaouen, Tétouan, Tanger, Assilah, Larache et Ksar El Kebir (Société PCN Consulting, SARL, documento não publicado). 
tinos de turismo balnear e às grandes cidades - imperiais ${ }^{15}$ e turísticas - privilegiadas pelos poderes públicos desde a década de 1970 até à década de 1990 (Berriane e Moizo 2016).

Em Chefchaouen, evoluiu-se de uma situação de quase inexistência de infraestruturas turísticas na década de 1970 - os turistas pernoitavam muitas vezes em casa dos habitantes locais (Thompson 2011) - para uma consolidação da oferta turística na década de 1990, a partir de iniciativas dos habitantes locais que vislumbravam no turismo uma oportunidade para diversificar e aumentar os seus rendimentos.

Mas será apenas a partir da década de 2000 que passa a existir uma estratégia concertada a partir do Ministério do Turismo marroquino em relação às potencialidades do turismo rural no país, ${ }^{16}$ traduzida na criação dos Pays d'Accueil Touristique (PAT), que pretendem constituir unidades físicas e culturais territorializadas, dotadas de uma identidade própria, e que em Chefchaouen - localidade pioneira dos PAT - tiveram o seu início em 2003. No entanto, e apesar de um expressivo setor turístico na região, a taxa de desemprego ronda os $20 \% .{ }^{17}$

Para além do turismo, a agricultura representa também um importante setor de atividade económica, com 183 hectares cultivados, ${ }^{18}$ numa localidade reconhecida pela sua forte componente agro-pastoril, na qual a população rural representará cerca de $87,2 \%$ da população total (recenseamento de 2019). ${ }^{19}$ No entanto, o relevo acidentado do território reduz consideravelmente as superfícies agrícolas úteis, pelo que a agricultura praticada é essencialmente uma agricultura tradicional de subsistência, que ocupa cerca de $85 \%$ da população ativa da região.

Neste sistema agrícola caraterizado pela existência de pequenas propriedades $(90 \%$ das propriedades agrícolas terão uma superfície inferior a cinco hectares), predomina a prática de policulturas, bem como a cultura predominante de variedades locais e a manutenção das culturas marginais e das práticas tradicionais de conservação da biodiversidade, num sistema de produção que procura integrar as lavouras com espécies florestais e pastagens. Assim, podemos encontrar na região pelo menos seis variedades de cereais, oito variedades de leguminosas e 15 variedades de fruta (Ater e Younes, 2008). Não obstante, a

15 Em Marrocos existem quatro cidades imperiais, todas capitais das antigas dinastias reinantes no país: Fez, Marraquexe, Rabat e Meknes. Estas cidades são frequentemente englobadas em circuitos turísticos intitulados "Cidades Imperiais".

16 Ministère du Tourisme (2002).

17 Réseau des Villes Euromed, < http:/www.reseau-euromed.org/fr/ville-membre/chefchaouen/ > (consultado a 18 de fevereiro de 2021 ).

18 Réseau des Villes Euromed, < http://www.reseau-euromed.org/fr/ville-membre/chefchaouen/ > (consultado a 18 de fevereiro de 2021 ).

19 Haut-Commissariat au Plan (2019). 
oliveira representa a principal cultura da região, ocupando $77 \%$ da superfície arbórea.

A criação local de cabras é igualmente expressiva, bem como um dos seus principais derivados - o queijo jben - queijo fresco feito a partir de leite de cabra e reconhecido local e internacionalmente. Existe igualmente uma fábrica de fiação de lã, bem como um universo de 20 cooperativas e cinco associações de artesãos que reúnem cerca de 900 dos 4000 artesãos existentes na localidade (Commune Urbaine Chefchaouen, s.d.). A região é ainda conhecida pela produção de carne de cabrito e uma grande diversidade de produtos lácteos (manteiga, smen ${ }^{20}{ }^{l e b e n}{ }^{21}$ e queijo), bem como pela produção de mel de alfarrobeira e de medronho.

\section{ALIMENTAÇÃO E PATRIMÓNIO: VALOR, DIFERENÇA E TERROIR}

Iniciada em $2010^{22}$ e contando já com mais de duas dezenas de inscrições em 2019, a transformação dos produtos, das práticas e dos consumos alimentares em património classificado pela UNESCO é um fenómeno que terá tendência para se multiplicar nos próximos anos. Como tal, acredito que as reflexões sobretudo aquelas que partem da etnografia - sobre os efeitos, os processos, os atores, as práticas e os discursos que estão na origem ou que resultam das classificações patrimoniais - poderão ser profícuas tendo em conta a proliferação de processos de patrimonialização em curso.

A forma como a inscrição na lista da UNESCO confere valor aos elementos classificados é um excelente auxiliar na transformação da Dieta Mediterrânica em produto turístico. Este valor, com origem numa distinção mundial, incorpora e certifica outros tantos valores, tais como a autenticidade, a integridade, a relevância e singularidade das práticas convertidas em património. A partir do conceito de cultura definido e utilizado pela UNESCO, ${ }^{23}$ a Dieta Mediterrânica é promovida como um elemento cultural, mas também como um estilo de vida que se relaciona com uma série de valores, tais como hospitalidade, vizinhança, convivialidade, diálogo intercultural e transmissão intergeracional.

20 Manteiga rançosa salgada que pode ser conservada, se preservada hermeticamente, por cerca de seis meses. É frequentemente utilizada em pratos de carne, mas pode igualmente ser utilizada em pastelaria.

21 O termo leben é geralmente utilizado para designar uma comida ou bebida feita a partir de leite fermentado. No norte de África, e nomeadamente em Marrocos, o leben é geralmente servido como bebida.

22 Com a classificação conjunta da Dieta Mediterrânica, da "Gastronomic Meal of the French", da "Traditional Mexican Cuisine - ancestral, ongoing community culture, the Michoacán paradigm" e do "Gingerbread craft from Northern Croatia".

23 UNESCO, 2003, Convention for the Safeguarding of Intangible Cultural Heritage, Article 2 (Definitions). 
Ao mesmo tempo, e tal como noutros processos de reconhecimento patrimonial pela UNESCO, a classificação da Dieta Mediterrânica assentava numa candidatura que mobilizava a narrativa comunidade-património (Crooke 2010), na tentativa de estabelecer uma conexão intrínseca e mutuamente legitimadora entre ambos - comunidade e património - que fosse, aprioristicamente, motivo suficiente para uma validação patrimonial. Mas, no caso concreto da Dieta Mediterrânica, por se tratar de uma candidatura transnacional, esta narrativa adquire, necessariamente, outros contornos, nomeadamente na definição e entendimento do que é, então, a comunidade.

A par com a presença de uma narrativa que enuncia a relação preexistente e simbiótica entre comunidade e património, narrativa cuja operacionalidade passa por diferentes estratégias e ativa diversos mecanismos de pertença identitária, neste caso, a construção de uma ideia de comunidade remete invariavelmente para uma formulação impregnada de referentes geográficos relativos às "populações mediterrânicas", que vai beber a diferentes fontes e que se presta, situacionalmente, a diferentes leituras e interpretações.

Não obstante, a Dieta Mediterrânica compreende um leque de práticas alimentares tão distintas e ao mesmo tempo tão difusas que, no âmbito de uma classificação transnacional, se torna complexo falar-se em produtos caraterísticos ou específicos relativos às práticas alimentares mediterrânicas de uma forma transversal.

O filme promocional feito pelas sete comunidades representativas da candidatura é exemplo disso mesmo: nele, para além da insistência da universalidade mediterrânica do consumo do pão e do azeite, poucos ingredientes ou práticas são eleitos como símbolos de uma alimentação universalmente mediterrânica. ${ }^{24}$ A produção teórica sobre o Mediterrâneo e a forma como uma ideia de "identidade mediterrânica" foi sendo construída (e reconfigurada), tem-se revelado, neste âmbito, um importante auxiliar na análise sobre as narrativas mobilizadas, pré e pós, classificação da Dieta Mediterrânica, bem como sobre as suas tentativas de transformação em produto turístico. ${ }^{25}$

Efetivamente, o que se vê neste pequeno filme são essencialmente imagens que remetem para um universo rural, onde a ideia de um passado pristino é exaltada enquanto modelo de boas práticas alimentares. Desta forma, o filme recorre frequentemente a um imaginário que procura a recriação de uma estética de "autenticidade", remetendo não raras vezes para a ideia de replicação de um universo rural e tradicional ligado ao passado, e à própria utilização

24 Disponível em < https://ich.unesco.org/en/Rl/mediterranean-diet-00884?include=film_inc.php\&i $\mathrm{d}=18849$ \&width $=700$ \& call $=$ film $>$ (última consulta em fevereiro de 2021).

25 Por exemplo Braudel (1987), mas também aquela enquadrada pela antropologia mediterranista, onde se destaca a produção de Peristiany (1988 [1965]) ou Albera, Blok e Bromberger (2001), bem como a de outros autores pertinentes no longo debate sobre o Mediterrâneo enquanto área de estudos. 
deste passado enquanto recurso (Tunbridge e Ashworth 1996; Bessière 1998; Aitchison, MacLeod e Shaw 2000).

Paralelamente, um dos passos para a transformação da comida em património ocorre quando é dotada de, ou lhe é reconhecida, uma dimensão coletiva, por via da comensalidade ou de uma ideia de passado partilhado, de ritual e repetição. Tal como refere Pfeilstetter (2015), a transformação da Dieta Mediterrânica em património cultural configura igualmente a comida comum, a comida do dia-a-dia, em comida diferente, quer qualitativamente (boa para a saúde e sustentável), quer culturalmente (mediterrânica e tradicional).

Não obstante, e tendo em conta a dificuldade em identificar consumos transnacionais mediterrânicos entre os sete países que representam a Dieta Mediterrânica, tem-se optado de uma forma estratégica por a definir enquanto "estilo de vida", retórica onde questões como a importância da sazonalidade e da produção local se ativam para a criação de produtos gastronómicos "autênticos" e "tradicionais" com uma forte componente de ligação ao território.

\section{ALIMENTAÇÃO E TURISMO: DE VOLTA AO TERROIR... E AO TERRITÓRIO}

Para muitos turistas, a alimentação e os consumos alimentares nos países visitados são a forma mais real de chegar à cultura local e de comunicar com os lugares. A comida apresenta-se como um bom veículo para consumir o outro a partir da ideia da existência de práticas alimentares intrinsecamente nacionais/regionais, e será também eventualmente a forma mais evidente e fácil de contacto com as sociedades visitadas e as diversas alteridades enunciadas. Para Lucy Long, "[...] food seems to provide us with a sense of the 'realness' of things. Because of food's commonality to all cultures, it allows us to experience the diversity within that commonality, providing us with groundedness from which we can embark on adventures into otherness" (Long 2004: 15).

Ao mesmo tempo, se o papel do turismo - e as suas transfigurações ao longo do tempo - não pode ser negligenciado na transformação do mundo e na sua contribuição para uma certa hegemonização dos consumos e práticas, depressa o setor do turismo percebeu que a alimentação pode constituir igualmente um elemento de diferenciação cultural, podendo ser símbolo de uma identidade nacional ou regional, constituindo essa capacidade de criação de diferença um recurso fundamental no contexto de um mercado global cada vez mais competitivo no que diz respeito a recursos e produtos turísticos (Hall e Sharples 2003).

Desta forma, a alimentação tem vindo progressivamente a ocupar terreno enquanto atração turística per se, afirmando-se como representante cultural e identitária de um país ou de uma região, refletindo quer a sua diversidade, 
quer as suas especificidades, e operando enquanto súmula e condensado cultural que atua através daquilo que é mais imediato e instintivo: as perceções sensoriais dos turistas através do paladar e do olfato, bem como a sua dimensão imperativa, tal como é referida por Bessière: "The emphasis on gastronomy is thus revealing, since it integrates eating into a new cultural world, from both a psychological and physiological standpoint" (Bessière 1998: 22).

Para Driss Boumeggouti (2006: 127), a possibilidade de consumo da alteridade através da alimentação teria caraterísticas específicas num contexto nacional como o marroquino, no qual o leitmotiv turístico seria o do contacto com todos os clichés relativos a uma ideia de exotismo oriental: opulência; explosão de cores, sabores e odores; variedade de especiarias e de aromas, aliados a um sincretismo subtil entre elementos da alimentação mediterrânica, africana, oriental e de outros lugares do mundo.

Creio, no entanto, que os efeitos da globalização transformaram substancialmente esta estafada projeção orientalista relativa à gastronomia marroquina. A importância do regional e do local e, consequentemente, o valor do território ligado aos consumos alimentares, recentram e focam a atenção nas especificidades regionais e na ideia de terroir ${ }^{26}$ como a verdadeira e insubstituível experiência gastronómica, mas igualmente, e tal como é referido por Bessière (1998), a ideia do mundo rural como o lugar por excelência de encontro de uma "identidade perdida", invariavelmente ligada à revitalização dos "bons velhos tempos" e das "boas velhas práticas alimentares".

Desta forma, é a partir da ideia da importância do local na alimentação, e da ancoragem dos produtos e das práticas alimentares a um lugar específico, que nasceram movimentos como o slow food, ${ }^{27}$ caraterizando-se por fazer a apologia de uma ideia de "globalização virtuosa" (Leitch 2013 [2009]), um novo figurino de cosmopolitismo que procura romper as oposições binárias rural/ urbano, local/global, reconfigurando a definição de localismo numa espécie de "ethical glocalism" (Leitch 2013 [2009]), e é com base nesta mesma ideia da existência de uma especificidade alimentar regional - bem como o seu terroir específico - que se consolidaram os pressupostos da existência de uma Dieta Mediterrânica em Chefchaouen.

26 Conceito vastamente discutido e problematizado pela antropologia da alimentação nas últimas décadas e que se traduz, em linhas gerais, na associação de um produto alimentar a um território ou a um lugar específico, criando um vínculo e uma conexão identitária entre ambos. Apesar de o conceito de terroir ter sido mais comummente associado ao universo vinícola, há muito que a sua influência se estendeu a outras esferas da gastronomia e dos consumos alimentares. Para uma leitura mais aprofundada sobre as questões do terroir ver, por exemplo, os trabalhos de Thomas Parker (2015) e Amy Trubek (2008).

27 Para uma leitura crítica sobre o movimento slow food ver, por exemplo, Parkins e Craig (2006), Leitch (2013 [2009]) ou West e Domingos (2011). 


\section{O típico, o tradicional e o selecionado: a Dieta Mediterrânica em Chefchaouen}

Voltando a uma das premissas deste texto, a maneira como a patrimonialização da Dieta Mediterrânica converte a comida comum em comida diferente, interessa então refletir sobre as várias formas como essa diferença é capitalizada, disputada e apropriada, em Chefchaouen. Uma das maiores evidências dessa capitalização assenta no modo através do qual diferentes produtos e serviços turísticos podem agora ser promovidos institucionalmente - e com legitimidade acrescida - enquanto tradicionais, autênticos e sustentáveis, a partir da sua ancoragem às práticas da Dieta Mediterrânica.

Um dos setores onde é mais evidente a transformação da Dieta Mediterrânica num produto é o da restauração. Se existe institucionalmente a tentativa de tornar a Dieta Mediterrânica numa mercadoria e, especificamente, num produto turístico, esta operação é, em Chefchaouen, muito mais operativa e eficaz quando é feita aparentemente fora da esfera institucional.

Para os turistas marroquinos parecem existir duas especialidades gastronómicas caraterísticas de Chefchaouen: a baissara ${ }^{28}$ e a tagine de anchovas. Já para os turistas internacionais, o setor da restauração local parece baralhar produtos de origem regional com produtos marroquinos, que não específicos da região de Chefchaouen. Desta forma, se para os agentes locais existe a tentativa de criar uma identidade gastronómica caraterística, com uma componente fortemente identitária, os símbolos dessa identidade acabam por ser, no fundo, um bricolage de várias práticas gastronómicas regionais de Marrocos. Veja-se a este respeito alguns menus destinados a turistas na medina de Chefchaouen. A ideia de "produtos da terra" ou de "menu tradicional" é no fundo uma amálgama de regionalismos marroquinos - como o amlou $^{29}$ - combinada com alguns modismos gastronómicos internacionais, como é o caso do hummus.

Não querendo aqui obscurecer aquilo que é proposto pelas ementas dos restaurantes em Chefchaouen, nem retirar legitimidade às mesmas, procuro apenas assinalar que a metamorfose operada, sob a égide da Dieta Mediterrânica, da comida do dia-a-dia em comida diferente, pode resultar em produtos e resultados diversos, eventualmente antagónicos, pouco coesos ou heterogéneos. Essa transformação, ao ser operada por distintos atores sociais - com diferentes formas de olhar e conceber o património - servirá sempre interesses e vontades múltiplas, revelando a plasticidade e a adaptabilidade de formas que as práticas alimentares podem adotar quando da sua transformação em património e, por conseguinte, mercadoria, afinal também ela sujeita à tensão existente entre oferta e procura.

28 Sopa espessa preparada com favas secas e azeite, altamente proteica, e que é geralmente servida ao pequeno-almoço durante o inverno na região de Chefchaouen.

29 Pasta espessa feita a partir de amêndoas trituradas, óleo de argão e mel. 


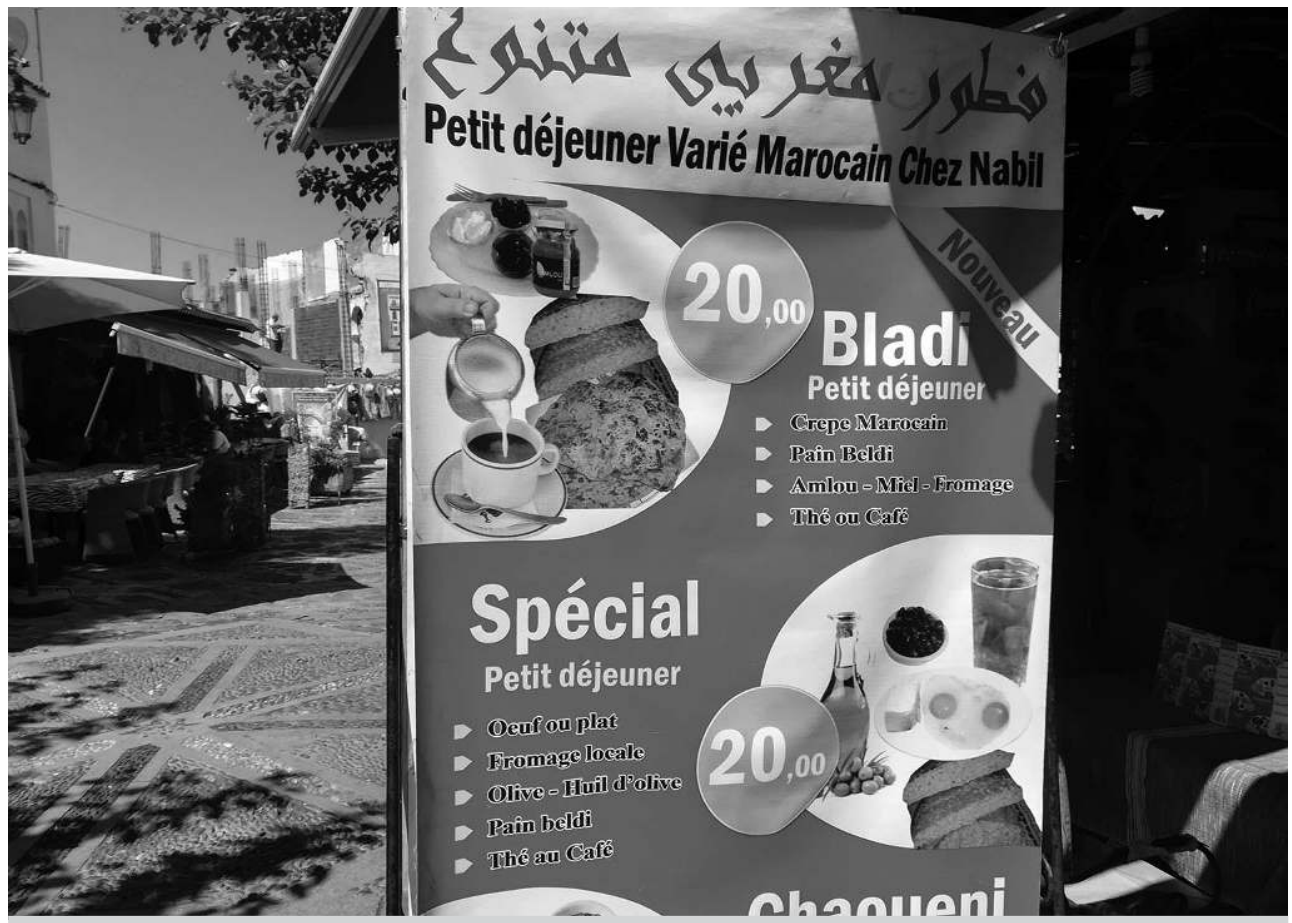

Figura 1 - Ementa de pequeno-almoço na praça Outa El Hamam. Fonte: Joana Lucas, Chefchaouen. Julho de 2017.

Paralelamente, as tentativas de transformação da Dieta Mediterrânica num produto turístico assentam invariavelmente na afirmação de valores como a "autenticidade", associados às culturas locais, ou a uma ideia de identidade reificada, valores que não raramente funcionam como reação às tendências da globalização.

Ahmed Skounti (2009: 74) refere sobre a aquisição do estatuto de património imaterial que esta tem regra geral duas implicações: por um lado, introduz uma distorção entre o património e o território que lhe deu origem, podendo esse mesmo património ser reproduzido em qualquer lugar do planeta através da mobilidade das pessoas e da mercadorização da cultura, enquanto, por outro lado, a produção de um património cultural imaterial implica o sacrifício de algo, na maior parte dos casos daquilo que transforma os próprios factos culturais em património.

Se a análise de Skounti faz sentido sobretudo quando inserida numa crítica mais ampla à globalização cultural, considero, no entanto, que os efeitos concretos da classificação da Dieta Mediterrânica enquanto património cultural imaterial em Chefchaouen questionam eles próprios a afirmação de Skounti na forma como estão dependentes de uma relação particularmente efetiva entre território e práticas alimentares que só pode ser ativada in loco. 
Assim, a questão que se coloca é a de que a Dieta Mediterrânica na sua dimensão transnacional não existe enquanto conjunto coerente de produtos, práticas alimentares e ingredientes de forma coesa e hegemónica. A Dieta Mediterrânica, na sua transformação em objeto patrimonial e em objeto de consumo, teve de ser inventada localmente e de forma diferenciada em cada território que deu origem à sua candidatura enquanto património cultural e imaterial junto da UNESCO.

Desta forma, a distorção de que fala Skounti entre o património e o lugar que lhe deu origem, tem em Chefchaouen o efeito inverso: aqui foi necessário conectar o património concetualizado de forma transnacional, e tendo o denominador "mediterrânico" como único em comum, com a realidade local e encontrar ou inventar correspondências entre produtos, ingredientes, práticas e o próprio território. É precisamente sobre esta invenção local da Dieta Mediterrânica que me irei deter de seguida.

\section{A INVENÇÃO INSTITUCIONAL DA DIETA MEDITERRÂNICA: CURADORIA E CONEXÃO}

Desde a sua primeira classificação pela UNESCO, em 2010, a Dieta Mediterrânica tem sido um dos principais temas dos projetos de desenvolvimento levados a cabo na região de Chefchaouen, tal como referido em alguns documentos oficiais. ${ }^{30}$ De entre uma série de projetos institucionais e programas de sensibilização despoletados pela classificação da Dieta Mediterrânica, irei destacar quatro iniciativas institucionais, que passarei a elencar e descrever, e que me foram apresentadas como sendo as mais relevantes no plano da divulgação e disseminação da Dieta Mediterrânica enquanto património cultural imaterial. ${ }^{31}$

30 "La municipalité de Chefchaouen est ainsi très engagée pour le développement durable et territorial de la ville et de ses alentours, notamment à travers un tourisme valorisant patrimoines naturels et culturels. La Diète Méditerranéenne constitue ainsi un pilier de la stratégie de la Commune de Chefchaouen, alliant le patrimoine naturel, agricole, paysager, gastronomique et culturel. La Municipalité de Chefchaouen s'est ainsi dotée d'un plan d'action de valorisation de la Diète Méditerranéenne et d'un plan d'action de marketing territorial et supporte activement certaines actions proposées dans la stratégie de développement du tourisme de la province de Chefchaouen, élaborée par l'ATED en partenariat avec la fondation ETEA et financée par l'Agence Espagnole de Coopération Internationale." (Diagnostic Agro-Paysager de la Ceinture Verte de Chefchaouen 2014: 11).

31 Todas estas iniciativas e/ou projetos são da iniciativa da Municipalité de Chefchaouen, em colaboração com agências para o desenvolvimento e ONG, aqui identificadas: Agencia Andaluza de Cooperación Internacional para el Desarrollo (AACID); Fondo Andaluz de Municipios para la Solidaridad Internacional (FAMSI); Junta de Andalucía - Programa de Cooperación Internacional; Réseau Méditerranéen des Médinas; Association Talassemtane pour l’Environnement et le Développement (ATED). 


\section{O Museu da Dieta Mediterrânica de Chefchaouen}

Ainda sem data de abertura prevista, o Museu da Dieta Mediterrânica de Chefchaouen resulta de uma iniciativa da Municipalité de Chefchaouen com o apoio da Agence pour la Promotion et le Développement du Nord. O museu deverá contar com uma sala de exposições permanentes, uma sala multimédia, uma loja de produtos locais, um espaço de degustação, um ponto de informação turística e um jardim botânico.

O conceito subjacente para o percurso expositivo do museu assenta na ideia da transição de etapas e processos "da paisagem para a mesa", conceção a partir da qual a progressão seria feita da seguinte forma: paisagem - agricultura - mulheres e Dieta Mediterrânica - comercialização - mercado - cozinha - mesa. ${ }^{32}$

O espaço dedicado ao mercado - souk ${ }^{33}$ - é tido como um espaço repleto de informações e estímulos, no qual os produtos específicos da região serão postos em evidência: pão, figos, medronheiro, arroubo (ou arrobe),$^{34}$ azeite, mel, leguminosas, cogumelos secos, lacticínios, ervas aromáticas, especiarias

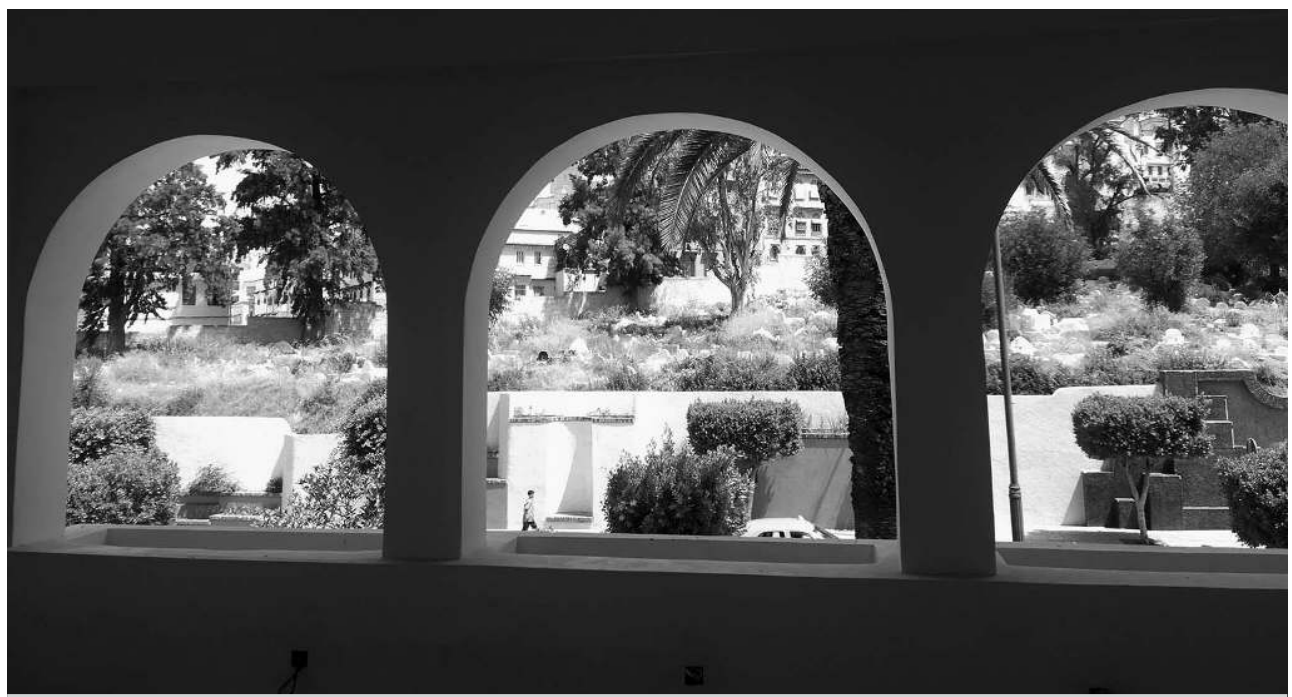

Figura 2 - Futuras instalações do Museu da Dieta Mediterrânica de Chefchaouen.

Fonte: Joana Lucas, Chefchaouen. Julho de 2017.

32 Sobre o percurso expositivo do museu e as suas etapas foi-me facultado no trabalho no terreno: Diversités \& Développement, s.d., Définition des Contenus du Musée Municipal de l'Alimentation Méditerranéenne, s.l., s.ed. Sobre as mulheres como "personagens centrais da alimentação no Mediterrâneo": idem, p. 2.

33 Termo geralmente utilizado para a designação de mercado no mundo árabe. A palavra pode ser usada para designar o mercado como um todo, um mercado especializado, ou ainda a parte comercial de um bairro por oposição a uma parte residencial (Geertz 1979: 126).

34 O arroubo (em árabe: rubb) é um preparado espesso entre o xarope e a compota, feito a partir de mosto de uva fermentado, e muito consumido na região de Chefchaouen. 
e condimentos. Será também reproduzida uma cozinha beldi (da terra/região) que irá ostentar, entre outros objetos, uma série de utensílios necessários à preparação da baisara, ${ }^{35}$ aqui identificada como o símbolo da culinária chauni (de Chefchaouen).

Está ainda prevista uma secção de caráter educativo onde existirá uma pirâmide alimentar, cujo objetivo é sensibilizar os visitantes para as questões de saúde ligadas à alimentação, e para os benefícios da Dieta Mediterrânica enquanto regime alimentar. Esta pirâmide alimentar será, no entanto, adaptada à realidade marroquina e, como tal, nela não constarão nem bebidas alcoólicas nem carne de porco, mas sim: “[...] borrego, espetadas, figos, figos da Índia, cuscuz, salsa e coentros, pastelaria marroquina, leben e bules de chá". ${ }^{36}$

\section{O pão: reabilitação de fornos tradicionais e criação de percursos turísticos}

Uma outra iniciativa levada a cabo pela Municipalité de Chefchaouen foi a reabilitação de fornos tradicionais destinados à cozedura de pão, com a colaboração da Agence Municipale de Développement de Chefchaouen (AMDC). Esta última refere-se, numa publicação de maio de 2017, à reabilitação de quatro fornos, inserindo-a numa estratégia de preservação do património arquitetónico, mas igualmente enquanto importante componente das práticas da Dieta Mediterrânica. O forno rif sabanin ${ }^{37}$ um dos mais emblemáticos da recente reabilitação, localiza-se numa área da cidade bastante turística e objeto, ela própria, de uma recente intervenção urbanística (Sebbanine, Ras El Maa), integrando o circuito turístico "Itinerário Histórico" promovido através de brochuras turísticas.

No entanto, a maioria dos fornos tradicionais para a cozedura de pão existentes na medina de Chefchaouen (cerca de 13) ostenta placas semelhantes em azulejo com o mesmo tipo de informação que o forno rif sabanin, não sendo clara a distinção entre as diferentes fases de reabilitação de fornos de pão por parte do município de Chefchaouen. Um outro forno integra o circuito turístico intitulado "Itinerário do Souk Beldi", tratando-se neste caso do forno de bab souk.

\section{Criação de uma marca de qualidade territorial:}

\section{Chefchaouen - Dieta Mediterrânica}

Igualmente iniciativa da Municipalité de Chefchaouen, a criação de uma marca de qualidade territorial em Chefchaouen, diretamente ligada à classifi-

35 Baisara: ver nota 25.

36 Diversités \& Développement, op. cit, p. 18.

37 Na placa em azulejo no exterior do forno pode ler-se: "Este forno foi construído com a fundação do Bairro Sebanin, durante o reinado do príncipe Mohamed Ben Rached (1540-1560)” (tradução minha). Esta informação está disponibilizada em árabe, castelhano e inglês. 


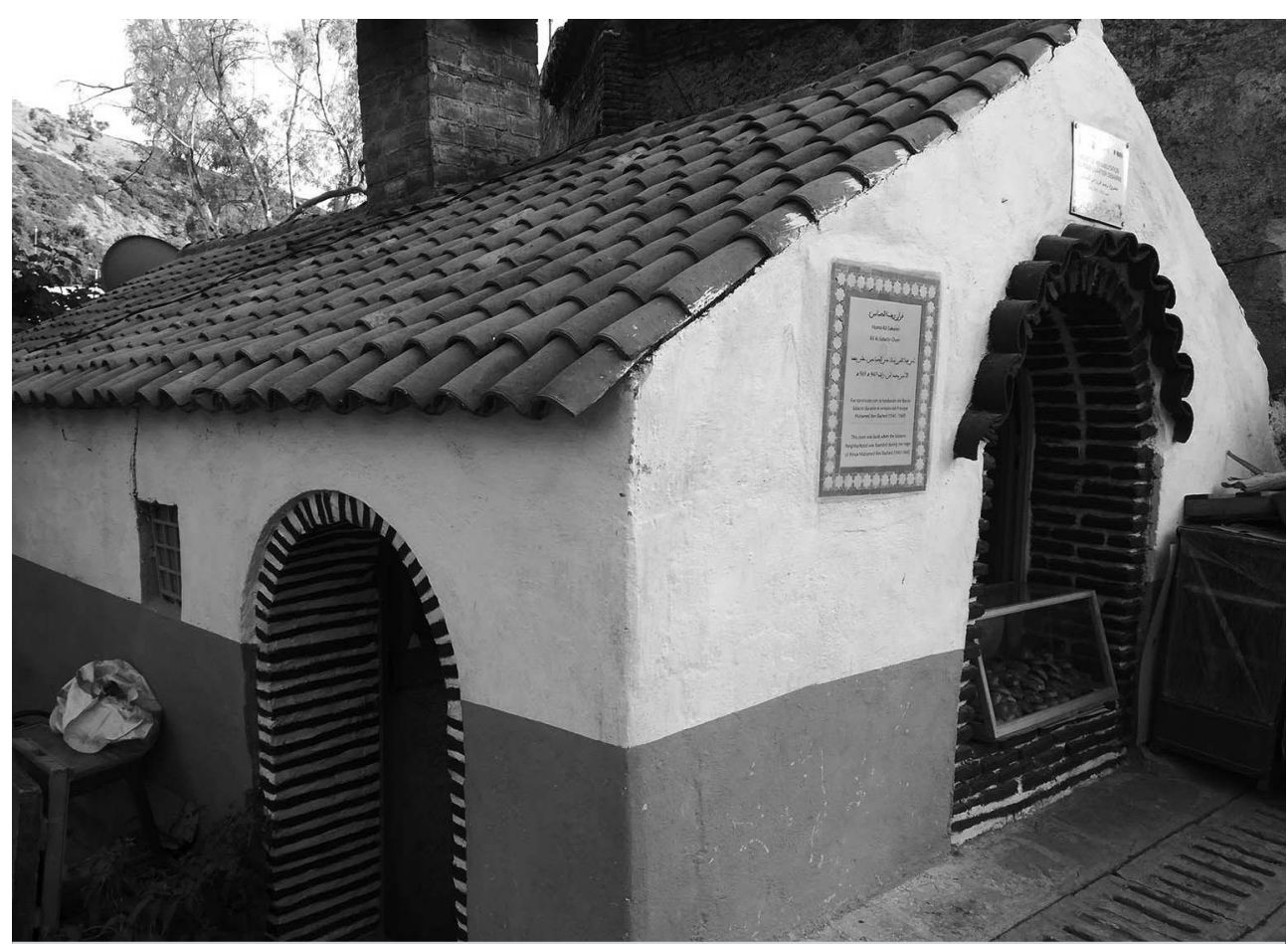

Figura 3 - Forno de pão rif sabanin. Fonte: Joana Lucas, Chefchaouen. Julho de 2017.

cação da Dieta Mediterrânica pela UNESCO, é descrita nas palavras de Mohamed Sefiani (presidente da Municipalité de Chefchaouen) como "[...] uma iniciativa de grande envergadura quer pelo seu impacto em setores diversos como o turismo, o artesanato, e o setor agroalimentar, quer pela quantidade de atores mobilizados e sua amplitude sobre o conjunto do território da região de Chefchaouen" 38 (tradução minha). Esta iniciativa, financiada pela Agência Espanhola de Cooperação Internacional e Desenvolvimento (AECID), e levada a cabo localmente pela Association Talassemtane pour l'Environnement et le Développement (ATED), passa pela integração dos agricultores nos processos de certificação desta marca territorial, cuja definição e implementação junto de restaurantes e hotéis locais está de momento em curso.

Estes produtos, que deverão ser "oriundos de produção local, respeitar o meio ambiente e estar em conexão com a Dieta Mediterrânica” (Diagnostic Agro -Paysager de la Ceinture Verte de Chefchaouen 2014: 70), correspondem à tentativa local de criação de uma marca de terroir que, apesar das iniciativas de diversas associações locais e ONG internacionais, não foi ainda concretizada. 


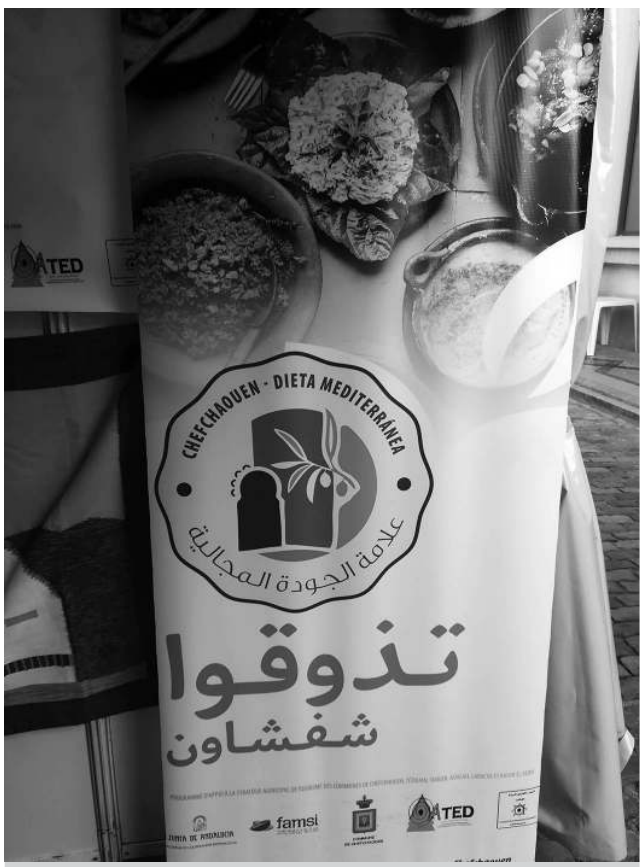

Figura 4 - Painel alusivo à criação da marca Chefchaouen - Dieta Mediterrânica. Fonte: Joana Lucas, Tavira. Agosto de 2019.

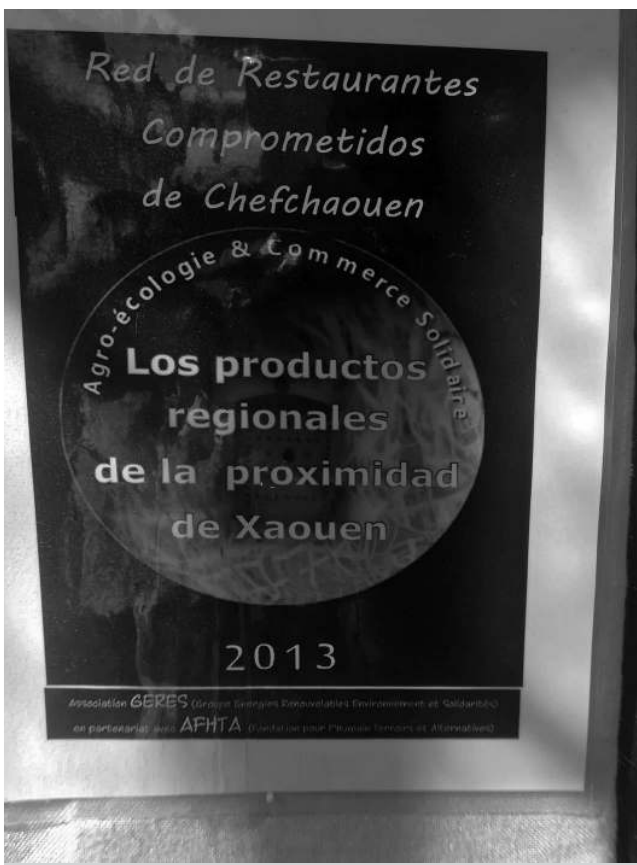

Figura 5 - Cartaz alusivo à rede de restaurantes comprometidos de Chefchaouen. Fonte: Joana Lucas, Chefchaouen. Julho de 2017.

Durante a minha estadia de terreno em Chefchaouen, em julho de 2017, pude observar a existência de algumas lojas de "produtos certificados", entre os quais azeite, vinagre de maçã de Imilchil (Alto-Atlas, região de Tafilalet), óleo de argão de Essaouira (região de Marraquexe - Tensift - Al Haouz), azeitonas, sal e mel, mas, à data, nenhum proveniente da região circundante. No entanto, segundo o funcionário de uma dessas lojas, os produtos alimentares que ali se vendiam não tinham muita procura quando comparados com os produtos cosméticos que também se vendiam nos mesmos estabelecimentos.

\section{Criação da rede de restaurantes comprometidos de Chefchaouen}

Em julho de 2017, num universo de 53 restaurantes, cinco integravam a rede de restaurantes comprometidos de Chefchaouen. Sob o mote "agro-écologie et commerce solidaire", esta rede procura promover e consolidar uma relação mais próxima com os produtores locais (nomeadamente das zonas rurais de Brikcha, Bouhachem e Talassemtane) na sua política de aquisições para a restauração, comprometendo-se com um montante mínimo anual de compras junto de agricultores certificados.

No entanto, apenas um dos cinco restaurantes aderentes ostenta, em lugar visível, a informação relativa à sua integração na rede de restaurantes 
comprometidos de Chefchaouen (figura 5), nos restantes quatro restaurantes aderentes essa informação não é exibida publicamente. Contudo, e tendo em conta as dinâmicas observadas relativas ao setor da restauração em Chefchaouen, o eventual sucesso comercial dos restaurantes locais está longe de passar pela ostentação desta informação, dependendo sim - como em tantos outros lugares do mundo - da sua pontuação em sites de restauração e gastronomia, bem como da sua popularidade e notoriedade junto de guias turísticos e habitantes da medina.

\section{AGÊNCIA E CRIATIVIDADE: OS ESPAÇOS EM BRANCO DA "DIETA MEDITERRÂNICA"}

Em suma, das quatro iniciativas institucionais aqui elencadas - não obstante as suas diversas dimensões e objetivos - nenhuma, em bom rigor, atua como promotora das práticas da Dieta Mediterrânica enquanto "bem" patrimonial: (1) um museu cujo projeto se encontra bloqueado por dificuldades de financiamento; (2) um conjunto de fornos de pão reabilitados cuja proposta de circuito pedonal não chega aos turistas; ${ }^{39}$ (3) uma marca de certificação regional que, apesar de inúmeras e louváveis iniciativas de envolvimento das comunidades locais - e apesar de existir já uma série de produtos alimentares que se encaixam no perfil enunciado - não saiu ainda do papel; (4) uma rede de restaurantes comprometidos que apenas angariou cinco restaurantes num universo onde existem dez vezes mais estabelecimentos.

Tudo isto revela-nos que as iniciativas de divulgação e promoção da Dieta Mediterrânica a partir da esfera das instituições locais - e a partir das estruturas que recebem financiamentos para o efeito (municipais e outras) - não são as que têm maior expressão naquele que é o quotidiano dos habitantes da região de Chefchaouen, nem eficácia junto dos turistas.

Desta forma, se é no plano institucional que a Dieta Mediterrânica é teorizada na sua relação com o território e com as comunidades que lhe servem de substrato, é no plano informal que ela se revela aos turistas e se deixa descobrir, ainda que - para mal da coerência proposta e pretendida pelas instituições que selecionam e elegem o que é ou não legítimo e válido enquanto património as escolhas (ou as condicionantes) dos atores informais sobre o que é ou não identificado como Dieta Mediterrânica, estão, não raras vezes, em dissonância com as definições institucionais.

Efetivamente, e ao contrário da maioria das classificações patrimoniais alimentares confirmadas pela UNESCO, a Dieta Mediterrânica constitui não só

39 Em julho de 2017, o posto de turismo, um pequeno quiosque de madeira localizado numa das entradas da medina, encontrava-se em construção. Na segunda estadia para trabalho de campo, em outubro de 2018, o quiosque, apesar de finalizado, encontrava-se fechado ao público e por inaugurar. 
um desafio perante a ideia de consolidação de uma identidade nacional e de afirmação de um Estado-nação, ${ }^{40}$ operativos por exemplo através da criação de gastro-nacionalismos (Kim 2016, sobre a classificação do kimchi sul-coreano; ou Matta 2014, sobre o peso do nacionalismo culinário no Peru), como questiona igualmente uma conceção transversal de mediterrânico, marcada por uma diversidade de práticas alimentares, interditos religiosos e usos dados aos mesmos ingredientes.

De facto, e porque se trata da invenção da Dieta Mediterrânica ao nível local ou, numa formulação mais otimista, da tentativa de encontrar produtos que se lhe possam adequar, essas escolhas podem em última análise ser sempre subjetivas e situacionais. Se os agentes institucionais têm do seu lado a legitimidade para definir o que integra (e o que fica de fora de) uma conceção local de Dieta Mediterrânica, os atores informais, apesar de não estarem formalmente mandatados para o efeito, acabam por consubstanciar, quer para os turistas, quer para a comunidade local, uma concetualização de Dieta Mediterrânica através das escolhas que fazem e dos produtos que glorificam no mercado da restauração que é, inequivocamente, o lugar onde os turistas e esta dieta se encontram. Enfim, a capacidade e a abrangência da promoção da Dieta Mediterrânica de uma forma democrática e transversal encontram-se, inequivocamente, nas mãos dos atores sociais que não estão vinculados a projetos e a instituições.

Finalmente, importa evidenciar a relação que inevitavelmente se estabelece entre a indeterminação do património (neste caso, da Dieta Mediterrânica, especialmente problemática) no seu processo de institucionalização (que se estabelece num plano virtual e discursivo) e a sua recriação ou transposição para a realidade concreta do território, por parte dos agentes e populações locais. São estes, afinal, quem detém o poder de livremente, através de uma inevitável recriação sem o peso ou os constrangimentos institucionais, dar livre expressão ao que pode comportar uma dieta mediterrânica.

40 Veja-se os casos da patrimonialização do Kimchi pela Coreia do Sul (2013) e pela Coreia do Norte (2015), ou do Lavash pela Arménia (2014) e pelo Arzebeijão, Turquia, Irão, Cazaquistão e Quirguistão (2016), ou ainda do café pela Turquia (2013) e pelos Emirados Árabes Unidos, Arábia Saudita, Omã e Qatar (2015). 


\section{BIBLIOGRAFIA}

AITCHISON, Cara, Nicola E. MACLEOD, e Stephen J. SHAW, 2000, Leisure and Tourism Landscapes: Social and Cultural Geographies. Londres, Routledge.

ALBERA, Dionigi, Anton BLOK, e Christian BROMBERGER (orgs.), 2001, L'Anthropologie de la Méditerranée. Paris, Maisonneuve et Larose/Maison Méditerranéenne des Sciences de l'Homme.

ARIZPE, Lourdes, e Cristina AMESCUA (orgs.), 2013, Anthropological Perspectives on Intangible Cultural Heritage. Nova Iorque e Londres, Springer.

ATER, Mohammed, e Hmimsa YOUNES, 2008, "Agrodiversity in the traditional agrosystems of the Rif mountains (North of Morocco)", Biodiversity, 9 (1): 78-81.

BENDIX, Regina, Aditya EGGERT, e Arnika PESELMANN (orgs.), 2012, Heritage Regimes and the State: Göttingen Studies in Cultural Property, Volume 6. Göttingen, Universitätsverlag Göttingen.

BERRIANE, Mohamed, e Bernard MOIZO, 2016, "Processus d'émergence d'une destination touristique rurale: le Pays de Chefchaouen", em Mohamed Berriane e Geneviève Michon (orgs.), Les Terroirs au Sud, vers un Nouveau Modèle? Une Expérience Marocaine. Rabat, IRD Editions/Faculté des Lettres et des Sciences Humaines de Rabat, 215-232.

BESSIERE, Jacinthe, 1998, "Local development and heritage: traditional food and cuisine as tourist attractions in rural areas", Sociologia Ruralis, 38 (1): 21-34.

BOUMEGGOUTI, Driss, 2006, "Le patrimoine culinaire dans la dynamique touristique marocaine”, Horizons Maghrébins - Le Droit à la Mémoire, 55: 122-132.

BRAUDEL, Fernand, 1987, O Mediterrâneo: O Espaço e a História. Lisboa, Teorema.

BRUlOTTE, Ronda L., e Michael DI GIOVINE, 2014, Edible Identities: Food as Cultural Heritage. Burlington, Ashgate.

Commune urbaine CHefChaOuen, s.d., Plan Communal de Développement 2010-2016, Document de Synthèse. Rabat, Direction Générale des Collectivités Locales, PNUD.

CROOKE, Elisabeth, 2010, "The politics of community heritage: motivations, authority and control”, International Journal of Heritage Studies, 16 (1-2): 16-29.

DIAGNOSTIC AGRO-PAYSAGER DE LA CEINTURE VERTE DE CHEFCHAOUEN, 20 14, disponível em < https://issuu.com/amdc7/docs/etude_diagnostic_agro-paysager_vega $>$ (última consulta em fevereiro de 2021).

GEERTZ, Clifford, 1979, "Suq: the bazaar economy in Sefrou”, em Clifford Geertz, Hildred Geertz e Laurence Rosen, Meaning and Order in Moroccan Society: Three Essays in Cultural Analysis. Cambridge, Cambridge University Press, 123-314.

HALL, Michael, e Liz SHARPLES, 2003, "The consumption of experiences or the experience of consumption? An introduction to the tourism of taste", em Michael Hall, Liz Sharples, Richard Mitchell, Niki Macionis e Brock Cambourne (orgs.), Food Tourism Around the World: Development, Management and Markets. Oxford, Elsevier, 1-24.

HARRISON, Rodney, 2013, Heritage: Critical Approaches. Londres e Nova Iorque, Routledge.

HAUT-COMMISSARIAT AU PLAN, 2019, Le Maroc en Chiffres. Rabat, Haut-Commissariat au Plan (editado com o apoio do BMCE Bank of Africa), disponível em < https://www. hcp.ma/downloads/Maroc-en-chiffres_t13053.html > (última consulta em fevereiro de $2021)$.

KIM, Chi-Honn, 2016, "Kimchi nation: constructing Kinjang as an intangible Korean heritage”, em Casey Man Kong Lum e Marc de Ferrière de Vayer (orgs.), Urban Foodways and 
Communication: Ethnographic Studies in Intangible Cultural Food Heritages Around the World. Londres, Rowmann \& Littlefield, 135-152.

KIRSHENBLATT-GIMBLETT, Barbara, 2004, "Intangible heritage as metacultural production", Museum International, 56: 52-65.

LABADI, Sophia, 2013, UNESCO, Cultural Heritage, and Outstanding Universal Value. Londres, Altamira Press.

LEITCH, Alison, 2013 [2009], “Slow food and the politics of 'virtuous globalization' ”, em Carolle Cunihan e Penny Van Esterik (orgs.), Food and Culture: A Reader. Londres e Nova Iorque, Routledge, 409-425.

LONG, Lucy, 2004, Culinary Tourism. Lexington, KY, The University Press of Kentucky.

LUM, Casey Man Kong, e Marc Ferrière LE VAYER (orgs.), 2016, Urban Foodways and Communication: Ethnographic Studies in Intangible Cultural Food Heritages Around the World. Londres, Rowmann \& Littlefield.

MATTA, Raúl, 2014, "República gastronómica y país de cocineros: comida, política, medios y una nueva idea de nación para el Perú", Revista Colombiana de Antropología, 50 (2): 15-40.

MINISTÈRE DU TOURISME, 2002, Stratégie de Développement du Tourisme Rural. Rabat, Ministère du Tourisme, Secrétariat Général, Bureau de Développement du Tourisme Rural, OMT, PNUD.

OBSERVATOIRE DU TOURISME MAROC, 2015a, Annuaire Statistique du Tourisme: Panorama des Performances Touristiques au Titre de l'Année 2015. Casablanca, Observatoire du Tourisme Maroc, disponível em < http://www.observatoiredutourisme.ma/wp-content/uplo ads/2017/03/Annuaire-Statistique-du-Tourisme-2015.pdf > (última consulta em fevereiro de 2021).

OBSERVATOIRE DU TOURISME MAROC, 2015b, Le Tourisme en Chiffres 2015. Casablanca, Centre d'Intelligence Economique, BMCE Bank, disponível em < http://www.observa toiredutourisme.ma/wp-content/uploads/2017/04/Tourisme-en-chiffres-2015.pdf > (última consulta em fevereiro de 2021 ).

PARKER, Thomas, 2015, Tasting French Terroir: The History of an Idea. Oakland, CA, University of California Press.

PARKINS, Wendy, e Geoffrey CRAIG, 2006, Slow Living. Londres, Bloomsbury.

PERISTIANY, J. G., 1988 [1965], Honra e Vergonha, Valores das Sociedades Mediterrânicas. Lisboa, Fundação Calouste Gulbenkian.

PFEILSTETTER, Richard, 2015, "Heritage entrepreneurship: agency-driven promotion of the Mediterranean diet in Spain”, International Journal of Heritage Studies, 21 (3): 215-231.

RUGGLES, D. Fairchild, e Helaine SILVERMAN (orgs.), 2009, Intangible Heritage Embodied. Nova Iorque, Springer.

SMITH, Laurajane, 2006, Uses of Heritage. Londres e Nova Iorque, Routledge.

SMITH, Laurajane, e Natsuko AKAGAWA (orgs.) 2009, Intangible Heritage. Londres e Nova Iorque, Routledge.

SKOUNTI, Ahmed, 2009, “The authentic illusion: humanity's intangible cultural heritage, the Moroccan experience”, em Laurajane Smith e Natsuko Akagawa (orgs.), Intangible Heritage. Londres e Nova Iorque, Routledge, 74-92.

THOMPSON, Elisabeth, 2011 , Implementation of Ecotourism for the Conservation of Natural Resources in Protected Areas: a Case Study of Talassemtane National Park, Chefchaouen, Morocco. Montpellier, AgroParisTech-Engref, relatório de estágio de mestrado em Foresterie Tropicale Durable. 
TRUBEK, Amy, 2008, The Taste of Place: A Cultural Journey into Terroir. Oakland, CA, University of California Press.

TUNBRIDGE, John E., Gregory J. ASHWORTH, 1996, Dissonant Heritage: The Management of the Past as a Resource in Conflict. Londres, Belhaven Press.

VIGNET-ZUNZ, Jacques Jawhar, 2014, Les Jbala du Rif: des Lettrés en Montagne. Casablanca, Editions la Croisée des Chemins.

WEST, Harry G., e Nuno DOMINGOS, 2011, "Gourmandizing poverty food: the Serpa cheese slow food presidium”, Journal of Agrarian Change, 12 (1): 120-143. 